\title{
Targeting of nucleo-cytoplasmic transport factor exportin 1 in malignancy (Review)
}

\author{
SIBEL ÖZDAŞ and İPEK CANATAR \\ Department of Bioengineering, Faculty of Engineering Sciences, Adana Alparslan Türkeş Science and \\ Technology University, Adana 01250, Turkey
}

Received September 3, 2021; Accepted December 3, 2021

DOI: $10.3892 / \mathrm{mi} .2021 .27$

\begin{abstract}
Nuclear pore complexes (NPCs) regulate the entry and exit of molecules from the cell nucleus. Small molecules pass through NPCs by diffusion while large molecules enter and exit the nucleus by karyopherins, which serve as transport factors. Exportin-1 (XPO1) is a protein that is an important member of the karyopherin family and carries macromolecules from the nucleus to the cytoplasm. XPO1 is responsible for nuclear-cytoplasmic transport of protein, ribosomal RNA and certain required mRNAs for ribosomal biogenesis. Furthermore, XPO1-mediated nuclear export is associated with various types of disease, such as cancer, inflammation and viral infection. The key role of XPO1 in carcinogenesis and its potential as a therapeutic target has been demonstrated by previous studies. Clinical use of novel developed generation-specific XPO1 inhibitors and their combination with other agents to block XPO1-mediated nuclear export are a promising new treatment strategy. The aim of the present study was to explain the working mechanism of XPO1 and inhibitors that block XPO1-mediated nuclear export.
\end{abstract}

\section{Contents}

1. Nucleo-cytoplasmic transport

2. Structure of XPO1

3. Physiological function of XPO1 in cells

4. XPO1 export of protein

5. Single nucleotide polymorphisms (SNPs) of XPO1

6. XPO1 in cancer

7. Inhibitors of XPO1

8. Conclusion and future directions

Correspondence to: Dr Sibel Özdaş, Department of Bioengineering, Faculty of Engineering Sciences, Adana Alparslan Türkeş Science and Technology University, Engineering Faculty, 201/1 Çatalan Street, Adana 01250, Turkey

E-mail: sozdas@atu.edu.tr

Key words: nuclear pore complex, exportin 1, nuclear export, exportin 1 inhibitor

\section{Nucleo-cytoplasmic transport}

Nuclear pore complexes (NPCs) regulate the entry and exit of molecules from the cell nucleus. Small molecules $(\leq 30 \mathrm{kDa})$ pass through NPCs by diffusion. However, larger molecules, such as RNA and proteins, enter and exit the cell nucleus via proteins called karyopherins, which are transport factors (1). Karyopherins (nuclear-cytoplasmic transport receptors family) denote a family of receptors associated with transport of molecules between the cytoplasm and nucleus of eukaryotic cells and comprise $>19$ members (including importins, exportins and transportins) $(1,2)$. They are called karyopherins because they are found inside the nucleus in the karyoplasm (or nucleoplasm). Importins transport the cargo molecule from the cytoplasm to the nucleus, while exportins transport the cargo molecule from the nucleus to the cytosol. Moreover, transportins can transport molecules both from the nucleus to the cytoplasm and from the cytoplasm to the nucleus $(3,4)$.

Karyopherins recognise and select the cargo molecule from its target sequences and transport it across the nuclear membrane $(1,2)$. The nuclear target sequence is a short amino acid sequence, which enables the cargo molecule to be recognised by carrier karyopherins for entry and exit to the cell nucleus; it also determines the direction of transport (5). The nuclear target sequence recognised by importins when transporting the cargo molecule from the cytoplasm to the nucleus is referred to as the nuclear localization signal (NLS). The NLS sequence commonly comprises hydrophilic amino acids (especially lysine) $(2,3)$. The target sequence that is recognized by the exportins when transporting the cargo molecule from the nucleus to the cytoplasm is called the nuclear export signal (NES) (2-4,6). The NES sequence is a short peptide of 10-15 amino acids with 3-4 regular leucine-rich hydrophobic amino acid repeats (generally conserved sequence $\Phi 1-\mathrm{X}_{2,3}-\Phi 2-\mathrm{X}_{2,3}-\Phi 3-\mathrm{X}-\Phi 4$, where $\Phi$ is leucine, valine, isoleucine, phenylalanine or methionine and $X$ is any amino acid) (7). Various mechanisms, such as post-translational modification (phosphorylation, acetylation, sumoylation), mutation or protein interaction, lead to changes in the intracellular location of the cargo molecule via the creation of new NES/NLS sequences, thus concealing the target sequence or changing the affinity of karyopherins to the cargo molecule $(8,9)$.

The transfer of molecules larger than $30 \mathrm{kDa}$ from NPCs, which cannot pass through the NPC by diffusion, is 
an energy-dependent process, and the function of importins and exportins is mediated by Ras-related nuclear protein (Ran). To perform their function, importins bind to Ran/GDP, whereas exportins bind to Ran/GTP (10). Exportins creates a cargo-exportin-Ran/GTP ternary complex in the nucleus by facilitating binding between cargo molecules and RanGTP. As this complex passes from the NPC to the cytosol, Ran/GTP is hydrolysed, Ran/GDP is formed and exportin releases the cargo molecule in the cytoplasm and then returns to the nucleus $(11,12)$. By contrast, importins bind to RanGTP, releasing the cargo protein (2).

\section{Structure of XPO1}

In the human genome, exportins are encoded by six genes, one of the primary nuclear exporters is the Exportin-1 (XPO1) gene, also known as CRM1 (Ensembl no. ENSG000000828987). The XPO1 protein functions as a shuttle as a nuclear transport receptor between the cell nucleus and the cytoplasm $(13,14)$. The XPO1 gene was discovered by Adachi and Yanagida in Saccharomyces cerevisiae and Schizosaccharomyces pombe cells in 1989. Mutations in the XPO1 gene first observed in mutant yeast strains deform the chromosome structure and the XPO1 gene is associated with preservation of chromosome structure. Therefore, the gene product has been named chromosome region maintenance 1 (CRM1) (15). The $S$. pombe XPO1 protein is homologous to the human protein originally named CC112. Given this homology, it became referred to as XPO1 instead of CC112 (16). The XPO1 gene is localized in the 2p16 region of the second chromosome in humans (17). It consists of 60,778 bases organized into 25 exons and separated by 24 introns. This gene has 24 transcript variants. The XPO1 gene product is a $112 \mathrm{kDa}$ protein. This mature polypeptide consists of 1,071 amino acids (13); it is a modular protein consisting of numerous functional domains and mediates the transport of 220 proteins (18). Given that the N-terminal region of XPO1 protein (UniProtKB no. O149803) interacts with GTPase/Ran, it is believed that the affinity of its C-terminal region (707-1,034 residues) with cargo molecules is increased (19).

The C-terminal region (amino acids 707-1,027) of the CRM1 protein is composed of two U-shaped antiparallel $\alpha$-helices and the HEAT repeat 15A-21A crystal structure was reported in 2004. In the Protein Data Bank, 26 data show the crystal structure of XPO1 alone or its interaction complexes with different proteins (20). Various methods, such as X-ray crystallography and electron microscopy, have revealed that XPO1 displays conformational flexibility as a transporter protein (21). They also shed light on the X-ray structure of the XPO1-RanGTP-Snurportin 1 and XPO1-RanGTP-RanBP1 (Ran binding protein 1) complexes. HEAT 9 interacts with the NES sequence of cargo proteins, serving as an allosteric inhibitor and controlling formation of the complex $(22,23)$.

\section{Physiological function of XPO1 in cells}

XPO1 demonstrates weak binding with RanGTP in the nucleus and with the NES sequence of cargo molecules (24) However, when XPO1 simultaneously binds to RanGTP and to cargo molecules, its affinity for both increases by 500-1,000 times, and it passes from the NPC to the cytosol by forming a ternary complex (25). The hydrolysis of Ran/GTP to Ran/GDP in the cytoplasm decreases the affinity of XPO1 to cargo molecules by causing conformational changes in the protein structure, facilitating the release of cargo molecules (10-12) (Fig. 1). XPO1 and RanGDP pass through the NPC and return to the nucleus for a new transport cycle $(2,25)$.

The human XPO1 gene is expressed in a cell cycle-dependent manner; mRNA transcription begins during the $G_{1}$ phase of the cell cycle and increases during the $G_{2} / M$ phase (26). During interphase, the XPO1 protein is localized inside the nucleus near the nuclear membrane $(26,27)$. High XPO1 expression levels have been observed in the brain, thymus, lung, spleen, liver, heart, pancreas, skeletal muscle, prostate, testis, placenta, ovary, small intestine, colon and peripheral blood leukocytes $(14,19)$.

XPO1 mediates the transport of certain types of RNA, including viral/cellular mRNA, ribosomal RNA, transfer RNA and small nuclear RNAs (snRNAs), as well as various macromolecules, such as ribosomal subunit and NES-containing proteins rich in leucine, short peptide stretches containing hydrophobic residues, shuttle proteins, tumour suppressor proteins (TSPs), cellular or non-spliced or incomplete spliced RNAs of various viruses [such as human immunodeficiency virus (HIV)-1, human T-lymphotropic virus type-1 (HTLV-1) and influenza A] and HIV-1 Rev protein and HTLV-1 Rex protein that interact with Ran/GTP in the nucleus and cytosol $(4,19,23,28-30)$.

\section{XPO1 export of protein}

In the proteomic analysis of yeast cells, 285 proteins regulated by XPO1 were detected, with $45 \%$ of these containing known NES sequences (31). NES sequences for XPO1 comprise hydrophobic amino acids, including isoleucine, leucine, methionine, valine and phenylalanine (32). The NES sequences have a common conserved motif containing 10-15 amino acids with hydrophobic character [HX2-3HX2-3HXH, where $\mathrm{H}$ is a hydrophobic amino acid (such as isoleucine, leucine, methionine, valine and phenylalanine), $\mathrm{X}$ is any amino acid and the number is the potential number of repeats] (33). These hydrophobic amino acids form an $\alpha$-helix or the entire loop structure, thus allowing XPO1 to attach to the hydrophobic pocket (25). However, NES sequences are yet to be sufficiently defined, as evidenced by the fact that $<40 \%$ are known (7). The change in the cargo molecule's three-dimensional structure by mutation, phosphorylation and dephosphorylation results in the formation of a new NES to which XPO1 binds $(8,34,35)$. It also causes NES sequences to be lost or masked or leads to the emergence of new sequences by additional modifications, including ubiquitination (33-35), acetylation (34), 10 sumoylation (9) or binding protein to specific cofactors such as RanGTP. Therefore, it alters the affinity of XPO1 to the cargo molecule (36,37).

Nuclear export of proteins, including STAT, NF- $\kappa$ B, nucleophosmin (NPM)1, Ras association domain family member SF2, Merlin, TSPs, such as APC, p53, p73, forkhead box O (FOXO), IKB, BCR-ABL, eukaryotic translation initiation factor 4E, BRCA1, viral proteins, regulatory/pro-inflammatory $\mathrm{p} 21 \mathrm{CIP}, \mathrm{p} 27 \mathrm{Kip} 1$, retinoblastoma, anti-apoptotic proteins, such as NPM and AP-1 and oncogenic proteins, such as 


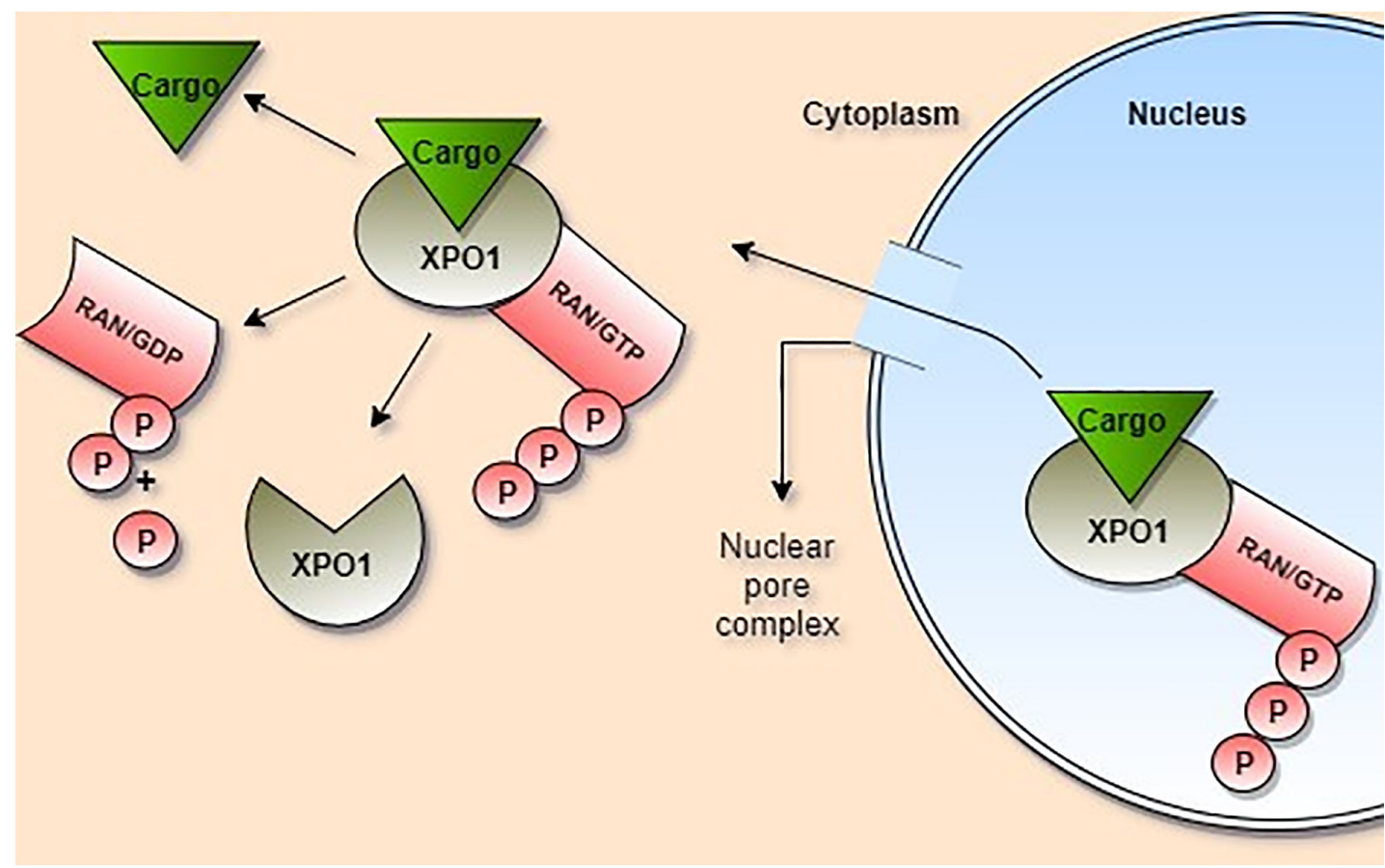

Figure 1. XPO1-mediated nuclear export. Ran/GTP and cargo bind to XPO1 and form a ternary complex. Afterwards, it passes through the nuclear pore complex. The affinity of XPO1 to the cargo molecule decreases because of hydrolysis of Ran/GTP to Ran/GDP in the cytoplasm. Subsequently, the cargo is released into the cytoplasm. XPO1, exportin 1; Ran, Ras-related nuclear protein; Phosphate, P.

Cox-2, c-MYC, epidermal growth factor receptor and hypoxia inducible factor-1, is key for cell cycle and cell proliferation. In addition, their nuclear export is mediated by XPO1 (38). Furthermore, XPO1 contributes to carcinogenesis by regulating the activity of TSPs and oncogenes. XPO1 controls multiple intracellular processes by regulating the localization of cyclin B, MPAK, MAPK-associated protein kinase 2, p21, p33, p27 and Survivin $(39,40)$. Moreover, the overexpression of XPO1 leads to transport of Rev and U snRNA from the nucleus to the cytoplasm (13). It has been reported that the transcription factors nuclear transcription factor Y/CBP (CREB-binding protein), Sp1 and p53 are associated with the promoter of the XPO1 gene and serve an important role in the transformation of cancer cells by activating the promoter of XPO1 (41). The XPO1 gene plays a role in the control of cell proliferation and affects the loss of control in cancer cell proliferation via various pathways. As a nuclear export factor, XPO1 regulates direct intracellular localization of cell cycle regulators, TSPs and pro-apoptotic proteins; therefore, the displacement of these proteins containing nuclear export sequences contributes to carcinogenesis and the development of drug-resistance mechanisms by regulating the activity of oncogenes.

\section{Single nucleotide polymorphisms (SNPs) of XPO1}

Genotypical variations in XPO1 may affect the function of the nuclear-cytoplasmic transport by altering expression levels of XPO1, resulting in emergence of certain disease phenotypes. The SNP c.1871A> G in XPO1 (pD624G) has been found to be associated with oesophageal squamous cell carcinoma and chronic lymphocytic leukaemia $(42,43)$. Structural modelling study have shown that it is necessary to create a critical salt bridge with lysine at position 144 in the area where aspartic acid amino acid located at 624 of the XPO1 protein attaches to the target cargo molecule of XPO1. It has been reported that the conversion of the amino acid at the position 624 to glycine may cause the loss of this salt bridge and increase the nuclear-cytoplasmic transport efficiency by changing the affinity of XPO1 to the cargo molecule (42). SNP rs6735330 in XPO1 is associated with autism (44). In addition, SNP rs7600515 in XPO1 has been reported as a prognostic factor for Crohn's disease (45). SNP rs4430924 in XPO1 is also associated with the risk of developing hepatotoxicity of anti-tuberculosis drugs (46).

\section{XPO1 in cancer}

XPO1 is reported to be overexpressed in certain types of cancer (Table I).

In ovarian (47), cervical (48), glioma (49), osteosarcoma (50), pancreatic (51), oesophageal $(52,53)$, lung $(54)$, gastric (55), head and neck (56,57), renal cell carcinoma (58), hepatocellular carcinoma (59), acute lymphoid leukaemia (ALL) $(60,61)$, chronic myeloid/lymphoid leukaemia (CML/CLL), multiple myeloma (MM) (62), mantle cell lymphoma (MCL) $(63,64)$ plasma cell leukaemia $(65)$, acute myeloid leukaemia (AML) (66) and breast cancer (67), an increase in the expression level of XPO1 was detected and it has been reported that this increase was associated with metastasis, increased tumour size, histological grade and decreased overall survival. The increased expression of XPO1 causes accumulation or mislocalisation of TSPs, cell cycle regulator and/or pro-apoptotic proteins in the cytoplasm with excessive nucleo-cytoplasmic transport, as well as deregulating ribosomal biogenesis, increasing carcinogenesis and 
Table I. Cancer types associated with exportin 1.

\begin{tabular}{|c|c|c|c|}
\hline Cell line & Study design & Cancer & (Refs.) \\
\hline $\begin{array}{l}\text { OVCAR-3, SKOV-3, CAOV-3, ES-2, A2780, Mdah2744, } \\
\text { OAW42, EFO21, EFO27, FU-OV-1, PA-1 }\end{array}$ & In vitro & Ovarian & (47) \\
\hline $\begin{array}{l}\text { HeLa (HPV18), SiHa (HPV16), CaSki (HPV16 and 18), } \\
\text { ME180, MS751 (HPV18), C33A }\end{array}$ & In vitro & Cervical & (48) \\
\hline U251, SHG-44 U118, U87 & In vitro and in vivo & Glioma & (49) \\
\hline U2OS, HOS, Saos2, MG63 & In vitro & Osteosarcoma & (50) \\
\hline MiaPaCa-2, HPAC, AsPC-1, PANC-1 & In vitro and in vivo & Pancreatic & (51) \\
\hline WHCO1, WHCO5, WHCO, ECA109, TE1, TE8, KYSE306 & In vitro and in vivo & Esophageal & $(52,53)$ \\
\hline A549, H460 & In vitro & Lung & (54) \\
\hline NCI-N87, SNU-1, SNU-16 & In vitro and in vivo & Gastric & (55) \\
\hline $\begin{array}{l}\text { UT-SCC-16A, UT-SCC-16B, UT-SCC-60A, UT-SCC-60B, } \\
\text { UT-SCC-74, UT-SCC-74B, }\end{array}$ & In vitro & Head and neck & $(56,57)$ \\
\hline e ACHN, Caki-1, 786-O & In vitro and in vivo & Renal cell carcinoma & (58) \\
\hline SK-HEP-1, Huh7, MHCC97H, SNU-182, SNU-387, HepG2 & In vitro and in vivo & Hepatocellular carcinoma & $(59)$ \\
\hline Plat-E, 293, OCI-AML-3, MOLM-13, and MV4 & In vitro & $\begin{array}{l}\text { Acute myeloid/lymphoid } \\
\text { leukemia (AML/ALL) }\end{array}$ & $(60,61)$ \\
\hline HS-5 & In vitro and in vivo & $\begin{array}{l}\text { Chronic myeloid/lymphoid } \\
\text { leukemia }\end{array}$ & $(62)$ \\
\hline HS-5 & In vitro and in vivo & Multiple myeloma & $(63)$ \\
\hline $\begin{array}{l}\text { JVM-2, Maver-1, NCEB-1, Jeko-1, DBsp53, Granta519, } \\
\text { JVM-13, Z-138, Rec-1 }\end{array}$ & In vitro and in vivo & Mantle cell lymphoma & $(64,65)$ \\
\hline $\begin{array}{l}\text { MM1S, MM1R, INA6, INA6GFP, ANBL6 KMS18, KMS20 } \\
\text { RPMI8226, MOLP8, 28BM, 12PE, XG1, U266 }\end{array}$ & In vitro and in vivo & Plasma cell leukemia & (66) \\
\hline 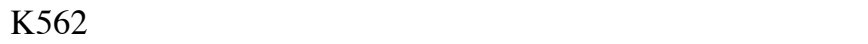 & In vitro & Acute myeloid leukemia & (67) \\
\hline
\end{tabular}

development of resistance to chemotherapy (10). In addition, Crm1-dependent pathways serve a role in cancer pathogenesis since it is active in the control of mitosis and the dispersion of chromosomes and is important in maintaining and chromosome protected structure (68). One study reported that XPO1 overexpression in all solid tumour types except liver cancer and haematological malignancies (69). Higher XPO1 expression has been associated with worse patient prognosis in ovarian, pancreatic, oesophageal, thymic epithelial and breast tumour, as well as glioma. On the other hand, high XPO1 expression has been associated with a better prognosis in patients with osteosarcoma. Given XPO1 overexpression and its association with negative clinical outcome in various types of malignancy, it has become an attractive potential therapeutic target molecule in oncology $(47,49-51,64)$.

\section{Inhibitors of XPO1}

It has been reported that suppressing XPO1-mediated nuclear export with specific agents or suppressing gene expression by XPO1-specific small interfering RNA activates apoptotic pathways and increases the sensitivity of tumour cells to chemotherapy drugs, such as doxorubicin, etoposide (70), cisplatin (71) and imatinib mesylate (72). Table II summarizes compounds that have been described as XPO1 inhibitors.

Numerous inhibitors of nuclear export derived from natural and synthetic sources have been identified (73).
Leptomycin B (LMB), a natural compound, emerged as the first inhibitory molecule to block the function of the XPO1 protein $(14,74)$. LMB is covalently bound at the specific cysteine (Cys528) residue located in the NES-binding cleft of the XPO1 protein; this inhibits binding of XPO1 to the target cargo molecule (74). LMB has been examined in multiple cancer cell lines and murine xenograft tumour models (75). Phase-I clinical LMB studies are continuing to investigate its use as an anti-cancer agent (70,75). However, LMB has not yet been used in clinical practice due to its low therapeutic index and high toxicity (76).

Other natural inhibitors of XPO1 include anguinomycins, isolated from Streptomyces species with selective cytotoxicity to transformed cells (77), and goniothalamin, obtained from Goniothalamus macrophyllus. Goniothalamin has been reported to induce $\mathrm{G}_{2} / \mathrm{M}$ phase cell cycle arrest and apoptosis in breast cancer cells $(78,79)$. Moreover, 15d-PGJ2, a prostaglandin family member with both anti- and pro-inflammatory properties (80) and plumbagin, derived from Plumbago zeylanica, have been shown to have a suppressive role in XPO1 nuclear export function. In the presence of plumbagin, interactions between XPO1 and Foxo1, p21, p53 and p73 are disrupted (81). In particular, plumbagin serves an anti-tumour effect via suppression of nuclear export (82). Furthermore, piperlongumine, an alkaloid of the long pepper, induces nuclear retention of major TSPs including Foxo1, p53, p21 and IкB- $\alpha$ and blocks interactions between XPO1 and these 
Table II. Exportin 1 nuclear export inhibitors.

\begin{tabular}{llc}
\hline Inhibitor & Compound & $($ Refs.) \\
\hline Leptomycin B & Antibiotic & $(14,74-76)$ \\
Anguinomycins & Antibiotic & $(77)$ \\
Goniothalamin & Natural & $(78,79)$ \\
15d-PGJ2 & Natural & $(80)$ \\
Plumbagin & Natural & $(81,82)$ \\
Piperlongumine & Natural & $(83,84)$ \\
Ratjadon & Antibiotic & $(85,86,87)$ \\
Curcumin & Natural & $(90,91)$ \\
SINE & Synthetic & $(92-100)$ \\
(R)-4'-methylklavuzon & Synthetic & $(101)$ \\
KOS-2464 & Synthetic & $(33,59)$ \\
CBS9106 & Synthetic & $(33)$ \\
Compound S109 & Synthetic & $(84,85,102)$ \\
PKF050-638 & Synthetic & $(33,73,103)$ \\
Compound 11 & Synthetic & $(104)$ \\
\hline
\end{tabular}

proteins $(83,84)$. The natural inhibitor ratjadon, isolated from Sorangium cellulosum, has anti-proliferative effects (85). In a previous study, ratjadon exerted anti-HIV activity (86). In one study, ratjadon was conjugated to small-molecule targeted ligands, which induced the inhibition of nuclear export in extracellular targeted cancer therapy. These conjugates retain their inhibitory activity by binding to XPO1 (87).

These aforementioned natural inhibitors with molecular mechanisms similar to LMB bind covalently to Cys528 in the reactive XPO1 region. XPO1-mediated nuclear export is inhibited by such binding, resulting in nuclear accumulation of TSPs and growth regulatory proteins (GRPs) $(88,89)$.

Contrary to the other natural XPO1 inhibitors, curcumin, a natural polyphenol product, also suppresses p53 nuclear export (90). Curcumin has various anti-inflammatory, antimicrobial, antioxidative and anti-cancer properties. Phase I/II studies of curcumin in multiple myeloma (MM) are ongoing (91).

Besides natural inhibitors, several synthetic compounds are also available to inhibit XPO1, including selective inhibitors of nuclear export (SINEs), KOS-2464, (R)-4'-methylklavuzon, CBS9106, Compound S109, PKF050-638 and Compound 11. SINE compounds are produced based on an in silico molecular modelling strategy (82-95). SINEs are covalently bound to Cys528 residue of XPO1 and hinder XPO1 binding to target cargo molecules (92). In in vivo studies, oral use of SINEs was observed to cause mild gastrointestinal symptoms (93). The potential of SINEs to inhibit XPO1-mediated nuclear export has been demonstrated. Apoptosis of cancer cells and arrest of cells in the $\mathrm{G}_{1}$ phase of the cell cycle are induced by SINEs $(62,93)$. The effectiveness of KPT-330 (selinexor), SINE compound, has been evaluated in clinical studies of solid tumours and haematological malignancy. The results of these clinical trials have shown it to be a promising therapeutic candidate $(10,94)$. KPT-330 has been found to have positive effects in clinical studies of hematopoietic malignancy, such as MM, AML and non-Hodgkin lymphoma
(NHL). KPT-330 has been subjected to phase I/II studies in patients with AML $(92,95)$. Notable decreases in tumour size have been demonstrated in a preclinical animal study with KPT-330. It has been demonstrated that KPT-330 has high efficacy in combination with various standard therapies, including selinexor/doxorubicin and selinexor/dexamethasone combinations $(96,97)$. Moreover, a decrease in XPO1 levels was observed in studies conducted with other SINEs, including KPT-185 and KPT-251 (98). Thus, the nuclear localisation of tumour suppressors may be preserved. Therefore, preclinical studies of XPO1 inhibition using SINE compounds may lead to a novel treatment for various types of cancer, including breast cancer $(18,97,99)$. In addition, activity of KPT-185 and KPT-276 was investigated in NHL using in vitro and in vivo study. A high level of anti-tumour activity was observed in mouse models in which KPT-276 was orally applied. Therefore, KPT-276 is a promising candidate for NHL treatment (100).

Another synthetic XPO1 inhibitor is (R)4'-methylklavuzon, which can retain tumour suppressor proteins in the nucleus by inhibiting the XPO1 protein. (R)-4'-methylklavuzon has been shown to be a novel drug candidate for treating hepatocellular carcinoma (101). KOS-2464, another synthetic molecule, is the most effective LMB analogue and has been reported to induce apoptosis at low nanomolar concentrations. Low toxicity and high anti-tumour activity of KOS-2464 have been demonstrated in various cancer cell lines and xenograft mouse models $(33,59)$.

CBS9106 binds to the XPO1 reactive site, causing degradation, and its anti-tumor activity has been demonstrated in in vitro in various cancer cell lines and in vivo in xenograft animal models (33). Compound S109 is a derivative of CBS9106 that causes cell cycle arrest of large TSPs mediated by XPO1. Its anti-tumour activity has been investigated in colorectal and kidney cancer cells and it has been proven to inhibit proliferation and induce cell cycle arrest in these cells $(84,85,102)$. Furthermore, PKF050-638 is a XPO1-inhibitor used in HIV treatment to inhibit the nuclear export of HIV-1 Rev protein; however, its anti-cancer effect has not been investigated yet $(33,103)$. PKF050-638 interacts with cysteine in the NES-binding groove and prevents binding of the NES, similar to the mechanism of LMB (73). (R)-6-[(2-isopropyl-5-methylphenoxy) methyl]-5,6-dihydro-2-Pyron (compound 11) is a colourless oily liquid. The cytotoxic effects of compound 11 in HGC27 and MGC803 gastric cancer cell lines have been investigated; compound 11 was reported to degrade XPO1, inducing apoptosis in both MGC803 and HGC27 cell lines, exhibiting strong cytotoxic and anti-tumour effects against these cells (104).

\section{Conclusion and future directions}

Studies have demonstrated the key role of XPO1 in carcinogenesis and its potential as a therapeutic target $(10,69)$. It has thus become the focus of efforts to develop new tumour treatment strategies. The clinical use of novel specific XPO1 inhibitors and their combination with other agents is promising. Suppressing gene expression with specific inhibitors or interference techniques have identified the biological function and intracellular mechanisms of XPO1 in malignancy, as well 
as drug resistance. Targeting XPO1 offers advantages in treatment strategies by activating various apoptotic pathways to avoid the development of drug resistance.

\section{Acknowledgements}

Not applicable.

\section{Funding}

No funding was received.

\section{Availability of data and materials}

Not applicable.

\section{Authors' contributions}

SÖ and İC contributed to acquisition and interpretation of data and drafted and wrote the manuscript. Data authentication is not applicable. All authors have read and approved the final version of the manuscript.

\section{Ethics approval and consent to participate}

Not applicable.

\section{Patient consent for publication}

Not applicable.

\section{Authors' information}

Sibel Özdaş, ORCID no. 0000-0003-4610-2785; İpek Canatar, ORCID no. 0000-0001-9448-8112.

\section{Competing interests}

The authors declare they have no competing interests.

\section{References}

1. Wente SR: Gatekeepers of the nucleus. Science 288: 1374-1377, 2000.

2. Watson J, Baker T, Bell S, Gann A, Levine M and Losick R: Molecular Biology of the Gene. 5th ed. Pearson/Benjamin Cummings: San Francisco Cold Spring Harbor, NY, 912 p. 2004

3. Izaurralde $\mathrm{E}$ and Adam $\mathrm{S}$ : Transport of macromolecules between the nucleus and the cytoplasm. RNA 4: 351-364, 1998.

4. Misteli T: Physiological importance of RNA and protein mobility in the cell nucleus. Histochem Cell Biol 129: 5-11, 2008.

5. Chook YM and Blobel G: Karyopherins and nuclear import. Curr Opin Struct Biol 11: 703-715, 2001.

6. Alberts B, Johnson A, Lewis J, Raff M, Roberts K and Walter P: Drosophila and the Molecular Genetics of Pattern Formation: Genesis of the Body Plan. 4th edition. Garland Science, New York, NY, 2002.

7. La Cour T, Kiemer L, Mølgaard A, Gupta R, Skriver K and Brunak S: Analysis and prediction of leucine-rich nuclear export signals. Protein Eng Des Sel 17: 527-536, 2004.

8. Powell SM, Zilz N, Beazer-Barclay Y, Bryan TM, Hamilton SR, Thibodeau SN, Vogelstein B and Kinzler KW: APC mutations occur early during colorectal tumorigenesis. Nature 359: 235-237, 1992.

9. Pichler A and Melchior F: Ubiquitin-related modifier SUMO1 and nucleocytoplasmic transport. Traffic 3: 381-387, 2002.
10. Azmi S, Uddin MH and Mohammad RM: The nuclear export protein XPO1 - from biology to targeted therapy. Nat Rev Clin Oncol 18: 152-169, 2021.

11. Pemberton LF and Paschal BM: Mechanisms of receptor-mediated nuclear import and nuclear export. Traffic 6: 187-198, 2005.

12. Kau TR, Way JC and Silver PA: Nuclear transport and cancer: From mechanism to intervention. Nat Rev Cancer 4: 106-117, 2004.

13. Fornerod M, Ohno M, Yoshida M and Mattaj IW: CRM1 is an export receptor for leucine-rich nuclear export signals. Cell 90: 1051-1060, 1997.

14. Kudo N, Khochbin S, Nishi K, Kitano K, Yanagida M, Yoshida M and Horinouchi S: Molecular cloning and cell cycle-dependent expression of mammalian CRM1, a protein involved in nuclear export of proteins. J Biol Chem 272: 29742-29751, 1997.

15. Adachi $Y$ and Yanagida M: Higher order chromosome structure is affected by cold-sensitive mutations in a Schizosaccharomyces pombe gene crm1+ which encodes a $115-\mathrm{kD}$ protein preferentially localized in the nucleus and its periphery. J Cell Biol 108: 1195-1207, 1989.

16. Ruggiero A, Giubettini M and Lavia P: XPO1 (exportin 1 (CRM1 homolog, yeast)). Atlas of Genetics and Cytogenetics in Oncology and Haematology. INIST-CNRS 16: 2011.

17. Fornerod M, van Baal S, Valentine V, Shapiro DN and Grosveld G: Chromosomal localization of genes encoding CAN/Nup214-interacting proteins-human CRM1 localizes to $2 \mathrm{p} 16$, whereas Nup88 localizes to $17 \mathrm{p} 13$ and is physically linked to SF2p32. Genomics 42: 538-540, 1997.

18. Parikh K, Cang S, Sekhri A and Liu D: Selective inhibitors of nuclear export (SINE)-a novel class of anti-cancer agents. J Hematol Oncol 7: 78, 2014.

19. Fornerod M, Van Deursen J, Van Baal S, Reynolds A, Davis D, Murti KG, Fransen J and Grosveld G: The human homologue of yeast CRM1 is in a dynamic subcomplex with CAN/Nup214 and a novel nuclear pore component Nup88. EMBO J 16: 807-816, 1997.

20. Petosa C, Schoehn G, Askjaer P, Bauer U, Moulin M, Steuerwald U, Soler-Lopez M, Baudin F, Mattaj IW and Müller CW: Architecture of CRM1/Exportin1 suggests how cooperativity is achieved during formation of a nuclear export complex. Mol Cell 16: 761-775, 2004.

21. Dölker N, Blanchet CE, Voss B, Haselbach D, Kappel C, Monecke T, Svergun DI, Stark H, Ficner R, Zachariae U, et al: Structural determinants and mechanism of mammalian CRM1 allostery. Structure 21: 1350-1360, 2013.

22. Saito N and Matsuura YA: 2.1-Â-resolution crystal structure of unliganded CRM1 reveals the mechanism of autoinhibition. J Mol Biol 425: 350-364, 2013.

23. Koyama M and Matsuura Y: An allosteric mechanism to displace nuclear export cargo from CRM1 and RanGTP by RanBP1. EMBO J 29: 2002-1013, 2010.

24. Lee SH and Hannink M: The N-terminal nuclear export sequence of IkappaBalpha is required for RanGTP-dependent binding to CRM1. J Biol Chem 276: 23599-23606, 2001.

25. Dong X, Biswas A, Süel KE, Jackson LK, Martinez R, Gu H and Chook YM: Structural basis for leucine-rich nuclear export signal recognition by CRM1. Nature 458: 1136-1141, 2009.

26. Ptasznik A, Nakat Y, Kalota A, Emerson SG and Gewirtz AM: Short interfering RNA (siRNA) targeting the Lyn kinase induces apoptosis in primary, and drug-resistant, BCR-ABL1(+) leukemia cells. Nat Med 10: 1187-1189, 2004.

27. Grunewald TG, Kammerer U, Schulze E, Schindler D, Honig A, Zimmer M and Butt E: Silencing of LASP-1 influences zyxin localization, inhibits proliferation and reduces migration in breast cancer cells. Exp Cell Res 312: 974-982, 2006.

28. Fukuda M, Asano S, Nakamura T, Adachi M, Yoshida M, Yanagida M and Nishida E: CRM1 is responsible for intracellular transport mediated by the nuclear export signal. Nature 390: 308-311, 1997.

29. Ossareh-Nazari B, Bachelerie F and Dargemont C: Evidence for a role of CRM1 in signal-mediated nuclear protein export. Science 278: 141-144, 1997.

30. Fei E, Ma X, Zhu C, Xue T, Yan J, Xu Y, Zhou J and Wang G: Nucleocytoplasmic shuttling of dysbindin-1, a schizophrenia-related protein, regulates synapsin I expression. J Biol Chem 285: 38630-38640, 2010.

31. Matsuyama A, Arai R, Yashiroda Y, Shirai A, Kamata A, Sekido S, Kobyashi Y, Hashimoto A, Hamamoto M, Hiraoka Y, et al: ORFeome cloning and global analysis of protein localization in the fission yeast Schizosaccharomyces pombe. Nat Biotechnol 24: 841-847,2006. 
32. Kutay U and Güttinger S: Leucine-rich nuclear-export signals: Born to be weak. Trends Cell Biol 15: 121-124, 2005.

33. Turner JG, Dawson J and Sullivan DM: Nuclear export of proteins and drug resistance in cancer. Biochem Pharmacol 83: 1021-1032, 2012

34. Vogt PK, Jiang $\mathrm{H}$ and Aoki M: Triple layer control: Phosphorylation, acetylation and ubiquitination of FOXO proteins. Cell Cycle 4: 908-913, 2005.

35. Craig E, Zhang ZK, Davies KP and Kalpana GV: A masked NES in INI1/hSNF5 mediates hCRM1-dependent nuclear export: Implications for tumorigenesis. EMBO J 21: 31-42, 2002.

36. Yoneda $\mathrm{Y}$, Hieda $M$, Nagoshi $\mathrm{E}$ and Miyamoto $\mathrm{Y}$ Nucleocytoplasmic protein transport and recycling of Ran. Cell Struct Funct 24: 425-333, 1999.

37. Poon IK and Jans DA: Regulation of nuclear transport: Central role in development and transformation? Traffic 6: 173-186, 2005

38. Gandhi UH, Senapedis W, Baloglu E, Unger TJ, Chari A Vogl D and Cornell RF: Clinical implications of targeting XPO1-mediated nuclear export in multiple myeloma. Clin Lymphoma Myeloma Leuk 18: 335-345, 2018.

39. Fabbro $M$ and Henderson BR: Regulation of tumor suppressors by nuclear-cytoplasmic shuttling. Exp Cell Res 282: 59-69, 2003.

40. Rensen WM, Mangiacasale R, Ciciarello M and Lavia P: The GTPase Ran: Regulation of cell life and potential roles in cell transformation. Front Biosci 13: 4097-4121, 2008.

41. van der Watt PJ and Leaner VD: The nuclear exporter, Crm1, is regulated by NFY and Sp1 in cancer cells and repressed by p53 in response to DNA damage. Biochim Biophys Acta 1809: 316-326, 2011

42. Lin DC, Hao JJ, Nagata Y, Xu L, Shang L, Meng X, Sato Y, Okuno Y, Varela AM, Ding LW, et al: Genomic and molecular characterization of esophageal squamous cell carcinoma. Nat Genet 46: 467-473, 2014.

43. Landau DA, Carter SL, Stojanov P, McKenna A, Stevenson K, Lawrence MS, Sougnez C, Stewart C, Sivachenko A, Wang L, et al: Evolution and impact of subclonal mutations in chronic lymphocytic leukemia. Cell 152: 714-726, 2013.

44. Liu X, Malenfant P, Reesor C, Lee A, Hudson ML, Harvard C, Qiao Y, Persico AM, Cohen IL, Chudley AE, et al: 2p15-p16. 1 microdeletion syndrome: Molecular characterization and association of the OTX1 and XPO1 genes with autism spectrum disorders. Eur J Hum Genet 19: 1264-1270, 2011.

45. Pernat Drobež C, Repnik K, Gorenjak M, Ferkolj I, Weersma RK and Potocnik U: DNA polymorphisms predict time to progression from uncomplicated to complicated Crohn's disease. Eur J Gastroenterol Hepatol 30: 447-455, 2018

46. He X, Zhang H, Tao B, Yang M, Chen H, Lu L, Yi H, Pan H and Tang S: The A/A genotype of XPO1 rs4430924 is associated with higher risk of antituberculosis drug-induced hepatotoxicity in Chinese patients. J Clin Pharmacol 59: 1014-1021, 2019.

47. Noske A, Weichert W, Niesporek S, Röske A, Buckendahl AC, Koch I, Sehouli J, Dietel M and Denkert C: Expression of the nuclear export protein chromosomal region maintenance/exportin $1 / \mathrm{Xpo}$ is a prognostic factor in human ovarian cancer. Cancer 112: 1733-1743, 2008.

48. Van der Watt PJ, Maske CP, Hendricks DT, Parker MI, Denny L, Govender D, Birrer MJ and Leaner VD: The Karyopherin proteins, $\mathrm{Crm} 1$ and Karyopherin $\beta 1$, are overexpressed in cervical cancer and are critical for cancer cell survival and proliferation. Int J Cancer 124: 1829-1840, 2009.

49. Liu X, Chong Y, Tu Y, Liu N, Yue C, Qi Z, Liu H, Yao Y, Liu H, Gao S, et al: CRM1/XPO1 is associated with clinical outcome in glioma and represents a therapeutic target by perturbing multiple core pathways. J Hematol Oncol 9: 108, 2016.

50. Jiang Y, Hou J, Zhang X, Xu G, Wang Y, Shen L, Wu Y, Li Y and Yao L: Circ-XPO1 upregulates XPO1 expression by sponging multiple miRNAs to facilitate osteosarcoma cell progression. Exp Mol Pathol 117: 104553, 2020.

51. Azmi AS, Li Y, Muqbil I, Aboukameel A, Senapedis W, Baloglu E, Landesman Y, Shacham S, Kauffman MG, Philip PA and Mohammad RM: Exportin 1 (XPO1) inhibition leads to restoration of tumor suppressor miR-145 and consequent suppression of pancreatic cancer cell proliferation and migration. Oncotarget 8: 82144-82155, 2017.

52. Van der Watt PJ, Zemanay W, Govender D, Hendricks DT, Parker MI and Leaner VD: Elevated expression of the nuclear export protein, $\mathrm{Crm} 1$ (exportin 1), associates with human esophageal squamous cell carcinoma. Oncol Rep 32: 730-738, 2014.
53. Yang X, Cheng L, Yao L, Ren H, Zhang S, Min X, Chen X, Zhang $\mathrm{J}$ and Li M: Involvement of chromosome region maintenance 1 (CRM1) in the formation and progression of esophageal squamous cell carcinoma. Med Oncol 31: 155, 2014.

54. Liu Z and Ga W: Leptomycin B reduces primary and acquired resistance of gefitinib in lung cancer cells. Toxicol Appl Pharmacol 335: 16-27, 2017.

55. Sexton R, Mahdi Z, Chaudhury R, Beydoun R, Aboukameel A, Khan HY, Baloglu E, Senapedis W, Landesman Y, Tesfaye A, et al: Targeting nuclear exporter protein XPO1/CRM1 in gastric cancer. Int J Mol Sci 20: 4826, 2019.

56. Özdaş $\mathrm{S}$ and Özdaş T: Crm1 knockdown by specific small interfering RNA reduces cell proliferation and induces apoptosis in head and neck cancer cell lines. Turk J Biol 42: 132-143, 2018.

57. Özdas S: Nuclear entrapment of p33ING1b by inhibition of exportin-1: A trigger of apoptosis in head and neck squamous cell cancer. Cell Mol Biol (Noisy-le-grand) 64: 66-72, 2018.

58. Inoue H, Kauffman M, Shacham S, Landesman Y, Yang J, Evans CP and Weiss RH: CRM1 blockade by selective inhibitors of nuclear export attenuates kidney cancer growth. J Urol 189: 2317-2326, 2013

59. Zheng Y, Gery S, Sun H, Shacham S, Kauffman M and Koeffler HP: KPT-330 inhibitor of XPO1-mediated nuclear export has anti-proliferative activity in hepatocellular carcinoma. Cancer Chemother Pharmacol 74: 487-495, 2014.

60. Conway AE, Haldeman JM, Wechsler DS and Lava CP: A critical role for CRM1 in regulating HOXA gene transcription in CALM-AF10 leukemias. Leukemia 29: 423-432, 2015.

61. Kojima K, Kornblau SM, Ruvolo V, Dilip A, Duvvuri S, Davis RE, Zhang M, Wang Z, Coombes KR, Zhang N, et al: Prognostic impact and targeting of CRM1 in acute myeloid leukemia. Blood 121: 4166-4174, 2013.

62. Lapalombella R, Sun Q, Williams K, Tangeman L, Jha S, Zhong Y, Goettl V, Mahoney E, Berglund C, Gupta S, et al: Selective inhibitors of nuclear export show that CRM1/XPO1 is a target in chronic lymphocytic leukemia. Blood 120: 4621-4634, 2012.

63. Zhang K, Wang M, Tamayo AT, Shacham S, Kauffman M, Lee J, Zhang L, Ou Z, Li C, Sun L, et al: Novel selective inhibitors of nuclear export CRM1 antagonists for therapy in mantle cell lymphoma. Exp Hematol 41: 67-78.e4, 2013.

64. Yoshimura M,Ishizawa J, Ruvolo V, Dilip A, Quintás-Cardama A, McDonnell TJ, Neelapu SS, Kwak LW, Shacham S, Kauffman M, et al: Induction of p53-mediated transcription and apoptosis by exportin-1 (XPO 1) inhibition in mantle cell lymphoma. Cancer Sci 105: 795-801, 2014.

65. Tai YT, Landesman Y, Acharya C, Calle Y, Zhong MY, Cea M, Tannenbaum D, Cagnetta A, Reagan M, Munshi AA, et al: CRM1 inhibition induces tumor cell cytotoxicity and impairs osteoclastogenesis in multiple myeloma: Molecular mechanisms and therapeutic implications. Leukemia 28: 155-165, 2014.

66. Wang AY, Weiner H, Green M, Chang H, Fulton N, Larson RA, Odenike O, Artz AS, Bishop MR, Godley LA, et al: A phase I study of selinexor in combination with high-dose cytarabine and mitoxantrone for remission induction in patients with acute myeloid leukemia. J Hematol Oncol 11: 4, 2018.

67. Yue L, Sun ZN, Yao YS, Shen Z, Wang HB, Liu XP, Zhou F, Xiang JY, Yao RY and Niu HT: CRM1, a novel independent prognostic factor overexpressed in invasive breast carcinoma of poor prognosis. Oncol Lett 15: 7515-7522, 2018.

68. Dasso M: Ran at kinetochores. Biochem Soc Trans 34: 711-715, 2006.

69. Sendino M, Omaetxebarria MJ and Rodríguez JA: Hitting a moving target: Inhibition of the nuclear export receptor XPO1/CRM1 as a therapeutic approach in cancer. Cancer Drug Resistance 1: 139-163, 2018.

70. Turner JG, Marchion DC, Dawson JL, Emmons MF, Hazlehurst LA, Washausen P and Sullivan DM: Human multiple myeloma cells are sensitized to topoisomerase II inhibitors by CRM1 inhibition. Cancer Res 69: 6899-6905, 2009.

71. Takenaka Y, Fukumori T, Yoshii T, Oka N, Inohara H, Kim HR, Bresalier RS and Raz A: Nuclear export of phosphorylated galectin-3 regulates its antiapoptotic activity in response to chemotherapeutic drugs. Mol Cell Biol 24: 4395-4406, 2004.

72. Aloisi A, Di Gregorio S, Stagno F, Guglielmo P, Mannino F, Sormani MP, Bruzzi P, Gambacorti-Passerini C, Saglio G, Venuta S, et al: BCR-ABL nuclear entrapment kills human CML cells: Ex vivo study on 35 patients with the combination of imatinib mesylate and leptomycin B. Blood 107: 1591-1598, 2006. 
73. Dickmanns A, Monecke T and Ficner R: Structural basis of targeting the exportin CRM1 in cancer. Cells 4: 538-568, 2015.

74. Kudo N, Matsumori N, Taoka H, Fujiwara D, Schreiner EP, Wolff B, Yoshida M and Horinouchi S: Leptomycin B inactivates CRM1/exportin 1 by covalent modification at a cysteine residue in the central conserved region. Proc Natl Acad Sci USA 96: 9112-9117, 1999.

75. Mutka SC, Yang WQ, Dong SD, Ward SL, Craig DA, Timmermans PB and Murli S: Identification of nuclear export inhibitors with potent anticancer activity in vivo. Cancer Res 69: 510-517, 2009

76. Newlands ES, Rustin GJ and Brampton MH: Phase I trial of elactocin. Br J Cancer 74: 648-649, 1996.

77. Hayakawa Y, Sohda KY, Shin-Ya K, Hidaka T and Seto H Anguinomycins $\mathrm{C}$ and $\mathrm{D}$, new antitumor antibiotics with selective cytotoxicity against transformed cells. J Antibiot (Tokyo) 48: 954-961, 1995.

78. Wach JY, Güttinger S, Kutay U and Gademann K: The cytotoxic styryl lactone goniothalamin is an inhibitor of nucleocytoplasmic transport. Bioorg Med Chem Lett 20: 2843-2846, 2010.

79. Sophonnithiprasert T, Mahabusarakam W, Nakamura Y and Watanapokasin R: Goniothalamin induces mitochondria-mediated apoptosis associated with endoplasmic reticulum stress-induced activation of JNK in HeLa cells. Oncol Lett 13: 119-128, 2017.

80. Hilliard M, Frohnert C, Spillner C, Marcone S, Nath A, Lampe T, Fitzgerald DJ and Kehlenbach RH: The anti-inflammatory prostaglandin 15-deoxy-delta(12,14)-PGJ2 inhibits CRM1-dependent nuclear protein export. J Biol Chem 285: 22202-22210, 2010.

81. Muqbil I, Azmi AS and Mohammad RM: Nuclear export inhibition for pancreatic cancer therapy. Cancers (Basel) 10: 138, 2018

82. Liu X, Niu M, Xu X, Cai W, Zeng L, Zhou X, Yu R and Xu K: CRM1 is a direct cellular target of the natural anti-cancer agent plumbagin. J Pharmacol Sci 124: 486-493, 2014.

83. Niu M, Chong Y, Han Y and Liu X: Novel reversible selective inhibitor of nuclear export shows that CRM1 is a target in colorectal cancer cells. Cancer Biol Ther 16: 1110-1118, 2015.

84. Niu M, Xu X, Shen Y, Yao Y, Qiao J, Zhu F, Zeng L, Liu X and $\mathrm{Xu} \mathrm{K}$ : Piperlongumine is a novel nuclear export inhibitor with potent anticancer activity. Chem Biol Interact 237: 66-72, 2015.

85. Meissner T, Krause E and Vinkemeier U: Ratjadone and leptomycin B block CRM1-dependent nuclear export by identical mechanisms. FEBS Lett 576: 27-30, 2004.

86. Fleta-Soriano E, Martinez JP, Hinkelmann B, Gerth K, Washausen P, Diez J, Frank R, Sasse F and Meyerhans A: The myxobacterial metabolite ratjadone A inhibits HIV infection by blocking the Rev/CRM1-mediated nuclear export pathway. Microb Cell Fact 13: 17, 2014.

87. Klahn P, Fetz V, Ritter A, Collisi W, Hinkelmann B, Arnold T, Tegge W, Rox K, Hüttel S, Mohr KI, et al: The nuclear export inhibitor aminoratjadone is a potent effector in extracellular-targeted drug conjugates. Chem Sci 10: 5197-5210, 2019.

88. Camus V, Miloudi H, Taly A, Sola B and Jardin F: XPO1 in B cell hematological malignancies: From recurrent somatic mutations to targeted therapy. J Hematol Oncol 10: 47, 2017.

89. Azmi AS, Muqbil I, Wu J, Aboukameel A, Senapedis W, Baloglu E, Bollig-Fischer A, Dyson G, Kauffman M, Landesman $\mathrm{Y}$, et al: Targeting the nuclear export protein XPO1/CRM1 reverses epithelial to mesenchymal transition. Sci Rep 5: 16077, 2015.

90. Theodoropoulos N, Lancman G and Chari A: Targeting nuclear export proteins in multiple myeloma therapy. Target Oncol 15 697-708, 2020
91. Niu M, Wu S, Mao L, Yang Y: CRM1 is a cellular target of curcumin: New insights for the myriad of biological effects of an ancient spice. Traffic 14: 1042-1052, 2013.

92.Etchin J, Montero J, Berezovskaya A, Le BT, Kentsis A, Christie AL, Conway AS, Chen WC, Reed C, Mansour MR, et al: Activity of a selective inhibitor of nuclear export, selinexor (KPT-330), against AML-initiating cells engrafted into immunosuppressed NSG mice. Leukemia 30: 190-199, 2016.

93. Etchin J, Sanda T, Mansour MR, Kentsis A, Montero J, Le BT, Christie AL, McCauley D, Rodig SJ, Kauffman M, et al: KPT-330 inhibitor of CRM 1 (XPO 1)-mediated nuclear export has selective anti-leukaemic activity in preclinical models of T-cell acute lymphoblastic leukaemia and acute myeloid leukaemia. Br J Haematol 161: 117-127, 2013.

94. Subhash VV, Yeo MS, Wang L, Tan SH, Wong FY, Thuya WL, Tan WL, Peethala PC, Soe MY, Tan DSP, et al: Anti-tumor efficacy of Selinexor (KPT-330) in gastric cancer is dependent on nuclear accumulation of p53 tumor suppressor. Sci Rep 8: 12248, 2018

95. Gravina GL, Senapedis W, McCauley D, Baloglu E, Shacham S and Festuccia C: Nucleo-cytoplasmic transport as a therapeutic target of cancer. J Hematol Oncol 7: 85, 2014.

96. Azizian NG and Li Y: XPO1-dependent nuclear export as a target for cancer therapy. J Hematol Oncol 13: 61, 2020

97. Lewin J, Malone E, Al-Ezzi E, Fasih S, Pedersen P, Accardi S, Gupta A and Abdul Razak A: A phase 1b trial of selinexor, a first-in-class selective inhibitor of nuclear export (SINE), in combination with doxorubicin in patients with advanced soft tissue sarcomas (STS). Eur J Cancer 144: 360-367, 2021.

98. Mendonca J, Sharma A, Kim HS, Hammers H, Meeker A, De Marzo A, Carducci M, Kauffman M, Shacham S and Kachhap S: Selective inhibitors of nuclear export (SINE) as novel therapeutics for prostate cancer. Oncotarget 5: 6102-6112, 2014.

99. Uddin MH, Zonder JA and Azmi AS: Exportin 1 inhibition as antiviral therapy. Drug Discov Today 25: 1775-1781, 2020.

100. Han X, Wang J, Shen Y, Zhang N, Wang S, Yao J and Shi Y: CRM1 as a new therapeutic target for non-Hodgkin lymphoma. Leuk Res 39: 38-46, 2015.

101. Delman M, Avcı ST, Akçok İ, Kanbur T, Erdal E and Çă̆ır A Antiproliferative activity of (R)-4'-methylklavuzon on hepatocellular carcinoma cells and $\mathrm{EpCAM}^{+} / \mathrm{CD} 133^{+}$cancer stem cells via SIRT1 and Exportin-1 (CRM1) inhibition. Eur J Med Chem 180: 224-237, 2019.

102. Liu X, Chong Y, Liu H, Han Y and Niu M: CRM1 inhibitor S109 suppresses cell proliferation and induces cell cycle arrest in renal cancer cells. Korean J Physiol Pharmacol 20: 161-168, 2016.

103. Daelemans D, Afonina E, Nilsson J, Werner G, Kjems J, De Clercq E, Pavlakis GN and Vandamme AM: A synthetic HIV-1 Rev inhibitor interfering with the CRM1-mediated nuclear export. Proc Natl Acad Sci USA 99: 14440-14445, 2002.

104. Xu HW, Jia S, Liu M, Li X, Meng X, Wu X, Yu L, Wang M and Jin CY: A low toxic CRM1 degrader: Synthesis and anti-proliferation on MGC803 and HGC27. Eur J Med Chem 206: 112708 , 2020 .

This work is licensed under a Creative Commons Attribution 4.0 International (CC BY 4.0) License. 